\title{
SLOPE STABILITY ANALYSIS CONSIDERING WEIGHT OF TREES AND ROOT REINFORCEMENT
}

\author{
Majid LOTFALIAN (1) ${ }^{*}$, Mehran NASIRI ${ }^{2}$, Amir MODARRES ${ }^{3}$, Wei WU ${ }^{4}$ \\ ${ }^{1,2}$ Department of Forestry, Sari Agricultural Sciences and Natural Resources University, Sari, Iran \\ ${ }^{3}$ Department of Civil Engineering, Babol University of Technology, Babol, Iran \\ ${ }^{4}$ Institute of Geotechnical Engineering, University of Natural Resources and Life sciences, Vienna, Austria
}

Received 2 March 2019; accepted 26 June 2019

\begin{abstract}
We study the effect of roots of alder trees on soil reinforcement and slope stabilization. Two types of soil, i.e. Marl and Clayey soils and alders of three ages are considered. The slope stability is studied according to the tree indices based on tree age and soil type. The effect of root reinforcement on slope stability is considered by an additional cohesion. The stability analyses are carried out by the FEM. We perform parameter studies considering tree age, soil type and surcharge. The results indicate that soil type is effective on cohesion. The results also showed that with increasing age of trees from 7 to 15 years, the amount of additional root cohesion increased and with the increase of the age of trees to 20 years this amount slightly decreased. Also, with regard to a constant slope geometry, the type of soil and the uniform surcharge pressure, 7-year-old trees have shown better performance in slope stabilization. It has been observed that as the age of alder trees grows, although the amount of additional root cohesion increases, however, due to increased surcharge pressure, the overall slope stability factor decreases.
\end{abstract}

Keywords: embankment, alder, soil, stabilization, forest road.

\section{Introduction}

The activity of plant root systems to slope strengthening, environmental restoration and soil erosion control has received a lot of attention in recent years (Reubens, Poesen, Danjon, Geudens, \& Muys, 2007; Zhou \& Wang, 2018). The presence of roots within the soil increases, with respect to the case of soil without vegetation, the material effective cohesion with no significant change in its friction angle (Gentile, G. Elia, \& R. Elia, 2010). The main root related indices include density, depth, and tensile strength of root, which cause soil reinforcement (Wu, McKinnell III, \& Swanston, 1979; Reubens et al., 2007; Roering, Schmidt, Stock, Dietrich, \& Montgomery, 2003). The mechanical contribution to strength offered by vegetation is much greater than the influence of hydrological effects (Ali, Farshchi, Mu'azu, \& Rees, 2012). Slope stability is influenced by vegetation mechanical parameters: plant's root matrix system and surcharge due to presence of trees (Kokutse, Temgoua, \& Kavazović, 2016). By specifying root tensile strength and investigating their density in different layers of soil, it is possible to investigate their effect on stability of slopes (Genet et al., 2008). Root reinforcement estimation is still challenging because of the spatial variability of root distribution and root mechanical properties (Vergani, Schwarz, Cohen, Thormann, \& Bischetti, 2014). The root strength and density depend on such factors as tree species, plant conditions, type of soil, and type of the stand (Keyes \& Grier, 1981; John, Pandey, \& Tripathi, 2001; Schmidt, Roering, Stock, Dietrich, Montgomery, \& Schaub, 2001). The soil characteristics, such as chemical, physical, and mechanical characteristics, may influence the root characteristics including density in the soil's horizontal layers and its tensile strength. It is well recognized that plant roots can improve the shear strength of soils by their high tensile strength and closely spaced root matrix system (Chok, Jaksa, Kaggwa, \& Griffiths, 2015). Root of trees may change during the growth period and at different ages. Such changes may change the root density at different horizontal layers of soil as well as the root's tensile strength. Therefore, investigation of temporal and spatial variables dependent on the root changes may help the forest researchers in understanding effect of root of trees with varying ages on stability of soil. In addition, with investigating root of plants in different soils, role of soil on the change in various root indices can be found.

${ }^{*}$ Corresponding author. E-mail: mlotfalian@sanru.ac.ir 
Thus, influence of root of trees on stability of soils can be studied by calculating additional root cohesion resulting from presence of root in various soils as well as investigating surcharges, anchors, slope geometry, and soil characteristics.

In the current study, role of root of alder trees (Alnus subcordata C.A.Mey.) on reinforcement of embankments in forest roads is investigated. Alder trees are indigenous and the most common trees around the forest roads in Iran which can regenerate on exposed soils. In the current work, this tree as a reinforcer of soil embankments in the roads is examined considering the age of trees and soil type.

\section{Materials and methods}

\section{Study area}

The research area is located in forest roads in Mazandaran province in Hyrcanian forests of Iran with geographical longitude $36^{\circ} 8^{\prime}$ to $36^{\circ} 11^{\prime}$ north degrees and latitude $52^{\circ} 45^{\prime}$ to $52^{\circ} 49^{\prime}$ eastern degrees. The minimum altitude from the sea level is 360 meters and the maximum is 1490 meters. The climate of the studied area is affected by the Caspian Sea and its relative humidity is high throughout the year and its average is 80 percent. Frost occurs about 69 days per year at different altitudes in the studied region. Average precipitation in the area is $800 \mathrm{~mm}$, with a monthly maximum of 102 and a minimum of $51 \mathrm{~mm}$. According to the number obtained from the Embereger method, climate of the studied area is semi-humid to wet with cold winter. In terms of stratigraphy, it is composed of the sediments from the second geological period, the lower Jurassic and Cretaceous periods, among which the amount of Lower Jurassic sediments, known as Shemshak Formation in Iran, is the highest level. Rendzine and forest brown are the major types of soil with alkaline $\mathrm{pH}$.

\section{Methods}

In this research, three age classes including 7 years (up to $10 \mathrm{~cm}$ diameter), 15 years (average $15 \mathrm{~cm}$ diameter), and 20 years (average $25 \mathrm{~cm}$ diameter) were considered for sampling. Sampling and studying the biotechnological indices of alder tree root considering age of the tree can show that depending on the time, indices show what changes and to what extent they can influence stability of soils. However, one of the most effective factors on changes in the root index may be type of soil and its characteristics. Alder tree is able to grow in the soils with physically, mechanically, and even chemically inappropriate conditions. In the area under study for this specie, which constitute 7 percent of frequency of the species under study, is present in the soils with varying growing situation. Given goals of this study, effect of soil on stability of embankments is examined by investigating the root indices considering type of soil. The values of roots tensile strength generally depend on various factors: species, dimensions, morphology and spatial directions (Gentile et al., 2010).
The model of soil reinforcement by tree roots was originally proposed by Wu et al. (1979) considering MohrCoulomb Model:

$$
\tau_{s r}=C_{S}+C_{r}+\sigma \tan \phi
$$

where $\tau_{s r}$ is the shear stress on the failure plane, $C_{S}$ denotes soil cohesion, $C_{r}$ denotes additional root cohesion resulting from root presence in soil, $\sigma$ is normal stress on failure plane, and $\phi$ is internal soil friction angle.

Additional root cohesion by root can be calculated through following formula (Equation (2)), assuming that roots have an elastic property, they are essentially orientated perpendicularly to the surface of the slide, and the angle of internal friction is not affected by the root reinforcement:

$$
C_{r}=t_{r}(\sin \delta+\cos \delta \tan \varphi),
$$

where $t_{r}$ is average mobilized tensile strength of roots, and $\delta$ is angle of deformed roots considering shear surface. Value of $(\sin \delta+\cos \delta \tan \varphi)$ is considered between $1.04-$ 1.3 (Wu et al., 1979). It is considered as 1.2 in the current work.

In addition, $t_{r}$ is calculated using Equation (3):

$$
t_{r}=T_{r} \times a_{r},
$$

where $T_{r}$ denotes average tensile strength of roots and $a_{r}$ is area of root's cross-section.

With substitution of previous equation, it is:

$$
C_{r}=1.2\left(T_{r} \times a_{r}\right) .
$$

Considering changes in the root size, Equation (4) can be rewritten as Equation (5):

$$
C_{r}=1.2\left(\sum_{i=1}^{n} T_{r i} \frac{A_{r i}}{A_{s}}\right) .
$$

Therefore, level of additional root cohesion resulting from roots in different soil layers considering age of trees and type of soil can be calculated by measurement of roots' tensile strength given the diameter as well as obtaining RAR index for each layer of soil.

\section{Determining Stability Factor of slopes}

Stability factor of slopes was calculated considering the indices calculated for the trees in terms of age and type of soil using PLAXIS software. PLAXIS is a commercially available finite element code that can calculate stresses, strains and failure states of soil mechanical problems (Cofie, Koolen, \& Perdok, 2000). PLAXIS 8.6 was used in this work for stability analysis of slopes. In order to determine stability factor of embankment, slope geometry was simulated in the software, and data related to the factors affecting stability of embankments, including weight of trees and soil characteristics were entered into the software. The amount of force imposed due to weight of alder trees for a diameter of up to $10 \mathrm{~cm}$ was averaged about $300 \mathrm{~N}$, for an average diameter of $15 \mathrm{~cm}$, an average of about $800 \mathrm{~N}$, and an average diameter of $25 \mathrm{~cm}$ it was about $1400 \mathrm{~N}$. 
The weight of surcharge due to the presence of trees on the embankments was uniformly applied. According to the available information and soil mechanics test, the soil layers were simulated and their data were entered the PLAXIS Input package to analyze the slope stability. In addition, after entering the initial data, the meshes of the layers were done by applying the fine mesh to analyze the stability of slopes (Figure 1).

Following applying mesh, pore water pressure and stress in the soil was calculated and the corresponding model was introduced into PLAXIS Calculation software to determine the stability factor. In the current study, stability factor was calculated for two station (a cutslope and a fillslope) considering the conditions of the area under study, characteristics of which are given in Figure 2.

Slopes stability factor was calculated following completion of data related to soil layers and factors affecting slope stability through Phi-c reduction analysis (cohesion and internal friction factor). In order to investigate role of roots on stability of embankments, slope stability factor was calculated with and without presence of roots. With comparison of safety factors given indices under study at varying ages of trees and type of soil, their effect on slope stability was investigated.

Data were statistically compared following gathering data related to the root and soil. Prior to root related
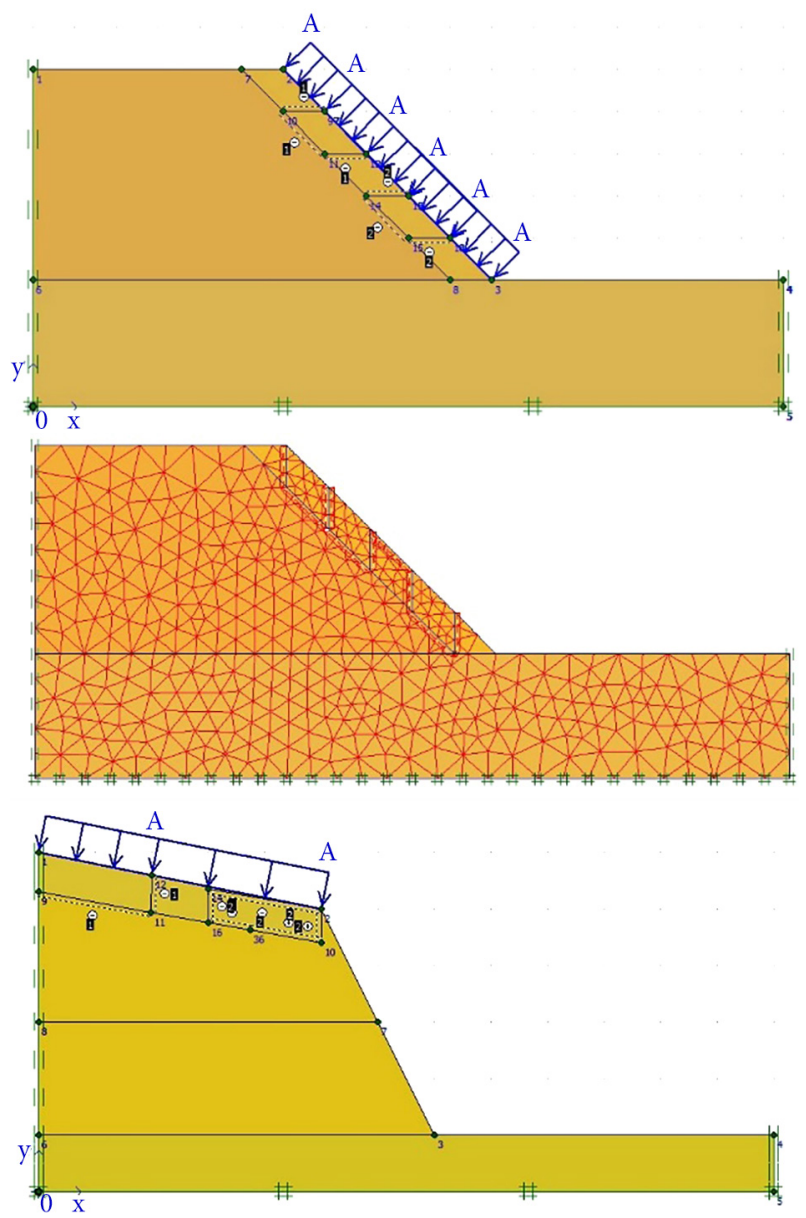

Figure 1. Entering data related to slope geometry and its elements and applying fine mesh for slope stability analysis

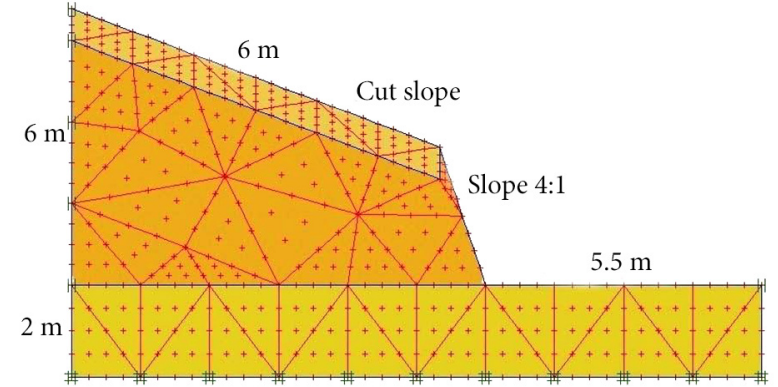

Figure 2. Geometric simulated model for cutslope and fillslope in forest roads

analysis, all data were examined in terms of normality and variance homogeneity using Kolmogorov-Smirnov test and Levene test. In case of non-normality of data, data normalization was done by log-transfer. ANOVA variance analysis and ANCOVA covariance analysis was used for comparing RBD, RAR indices, and additional root cohesion resulting from root presence for varying ages of alder trees considering depth of root. Averages were compared using Tukey-HSD test. The analyses, statistical calculations, and drawing diagrams related to embankments' stability reinforcement were done by STATISTICA and SigmaPlot 12.0 software.

\section{Results}

Determining additional root cohesion resulting from root

Results for calculation of additional root cohesion resulting from root presence in varying soil layers indicate that soil type affects level of cohesion. Additional root cohesion is reduced by increasing the depth, and it is more in clay loam soils for all layers of soil and for all ages than marl soil (Figure 3). In trees up to 7 years of age, the average cohesion in the soil layers for clay loam soils was $20.53 \mathrm{kPa}$ and $14.78 \mathrm{kPa}$ for marl soil. Nevertheless, it was calculated in 15-year-old trees for clay loam soil and Marl soil as 21.66 and $13.53 \mathrm{kPa}$ respectively. In trees more than 20 years, the average cohesion for clay loam soil and marl soil was 17.47 and $13.99 \mathrm{kPa}$, respectively. Also, the average cohesion in the $0-15 \mathrm{~cm}$ soil layer for clay loam and marl soils was 26.60 and $21.56 \mathrm{kPa}$ respectively, in the 15 to $30 \mathrm{~cm}$ layer, 19.56 and $15.56 \mathrm{kPa}$ respectively, In the

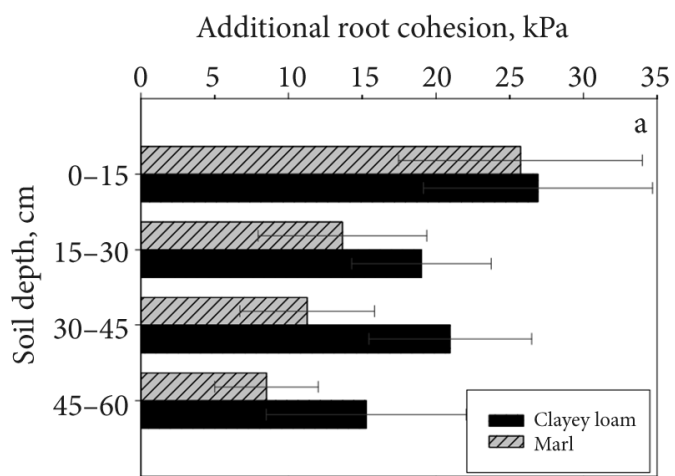

Figure 3. Additional root cohesion in different layers of the soil according to the age of the 7 
$30-45 \mathrm{~cm}$ layer, 17.53 and $11.07 \mathrm{kPa}$ respectively and in the $45-60 \mathrm{~cm}$ layer, respectively, it was calculated to be 15.82 and $8.21 \mathrm{kPa}$, respectively.

\section{Mechanical characteristics of study area soil}

Stability of embankments was studied for two stations in the forest roads, mechanical characteristics of its soil are given in Table 1. These characteristics were used for simulation of slope stability. In this table, the first station is related to cutslope with clay loam soil, and second station is related to fillslope with marl soil.

Table 1. Mechanical characteristics of soil in study area

\begin{tabular}{|c|c|c|c|c|c|c|c|}
\hline . & 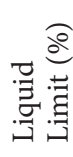 & 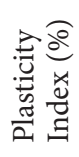 & 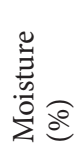 & 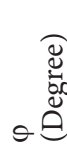 & 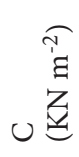 & $\begin{array}{r}\overparen{7} \\
Z \\
Z \\
Z\end{array}$ & 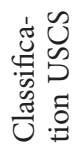 \\
\hline $\begin{array}{l}\text { First } \\
\text { (Cutslope) }\end{array}$ & 44.5 & 14.2 & 20.4 & 29 & 8 & 19 & ML \\
\hline $\begin{array}{l}\text { Second } \\
\text { (Fillslope) }\end{array}$ & 46.1 & 19.2 & 24.2 & 25 & 5 & 18 & CL \\
\hline
\end{tabular}

\section{Slope stability factor}

Slope geometry modeling and slope stability analysis in the first station (with trees with average age of $7-15$ years in mixed form) indicate that root of alder trees plays significant role in stability of soil layers. It is found that the roots not only cause reduction of the risk of slide in the layers where they are present (the top $60 \mathrm{~cm}$ ), but also reduce the slide-sensitive areas and increase stability of the underlying layers. Slide resistant areas were transferred from the top of the cutslopes to the paw of embankment, and the stability factor for the cutslopes unreinforced with alder tree's root was calculated to be 1.46, and 1.64 for the reinforced cutslopes (Figure 4). These numbers indicate that there is a risk of landslide in the region without

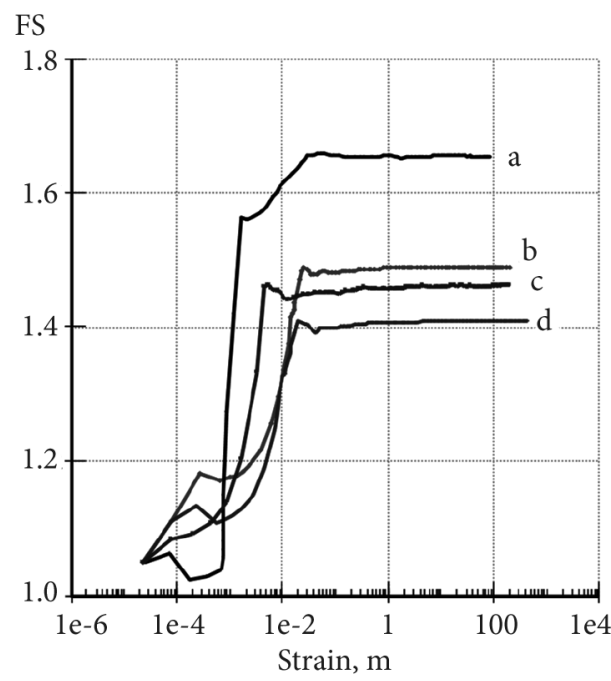

Figure 4. Slope stability factors in cases of reinforced and unreinforced with root of alder tree ( $a$, cutslope reinforced; $b$, fillslope reinforced; c, cutslope unreinforced and d, fillslope unreinforced) presence of the root. For the second station (trees with an average age of 7 years), the same is true on the fillslope. The presence of roots reduces the areas susceptible to slide and increases the slope stability factor from 1.41 to 1.49 . Due to the fact that the soil in the second station is marl type with a Plasticity index of 19.2, the roots of trees have been able to play a significant role in preventing landslide in the area.

\section{Effect of age on slope stability factor}

Effect of age of trees on slope stability was examined with assuming fixed embankment geometry, soil type, and considering uniform loading (weight of trees in terms of age). Results showed 7-years-old trees outperform regarding stability of soil layers compared to 15 and 20 yearsold trees (Figure 5). Contribution of the underlying layers
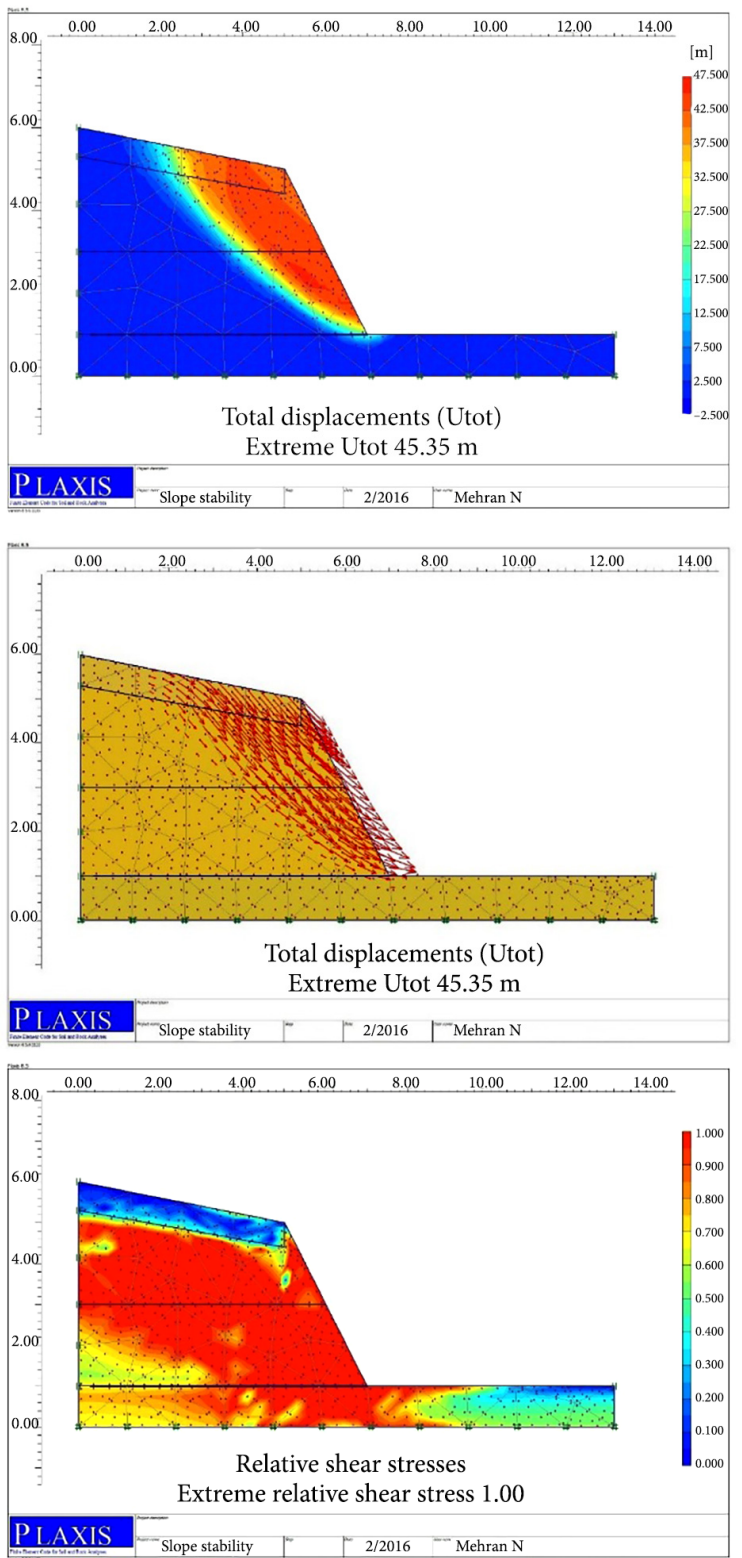

Figure 5. Modeling slope stability for 7-years-old trees (the figures indicate stability analysis, orientation of forces, and status of relative tension in the soil layers from top to down, respectively) 
susceptible to slide for 7-year-old trees is much less than those with 15 years old and 20 years old. In addition, tension analysis shows that tension level in the soil mass

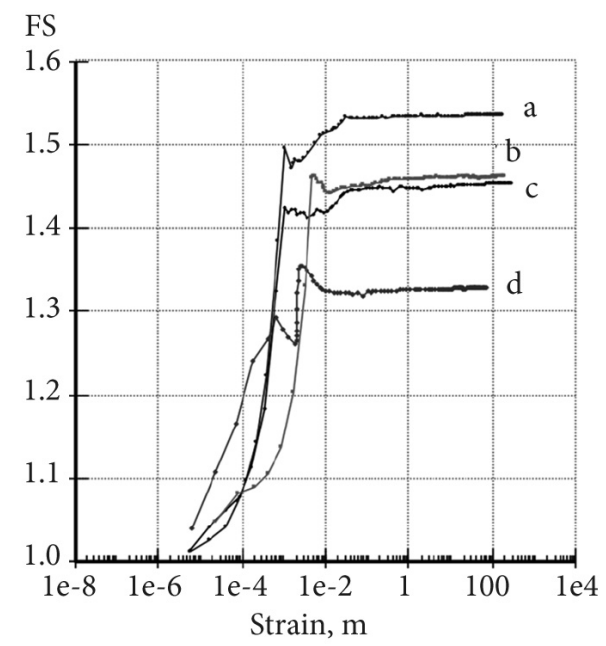

Figure 6. Slope Stability factors for varying ages of alder trees ( $a, 7$ years old; b, 15 years old; c, without tree and d, 20 years old)
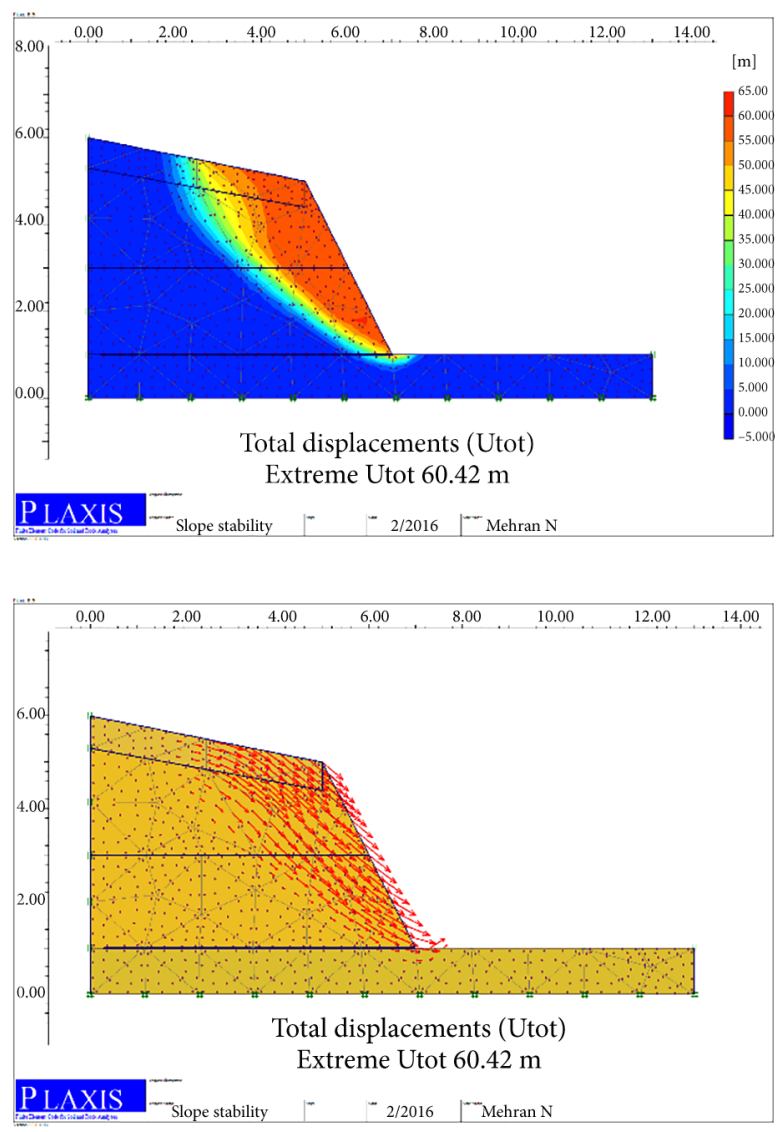

Figure 7. Modeling slope stability for 15 -years-old trees by applying ML soil characteristics (the figures indicate stability analysis and orientation of forces from top to down, respectively) increases by increasing age of trees, and the role of roots on soil stability decreases in 20-year-old trees. The contribution of the relative tension in the roots where roots are present is very low, but in 20-year-old trees it is observed that the tension is transmitted to the upper layer of soil due to the diameter increase (tree weight). Calculation of slope stability factor for various trees in terms of age indicated that this factor is larger in 7-years-old trees (FOS $=1.54)$ compared to 15 -years-old trees $(\mathrm{FOS}=1.47)$ and 20 -years-old trees $(\mathrm{FOS}=1.33$ ) (Figure 6). Calculations showed the respective slope is in the better situation in terms of stability factors without presence of trees (FOS = 1.45) compared to presence of 20 -years old trees.

\section{Effect of soil on slope stability factor}

The role of soil type on the slope stability was studied and analyzed by modeling the characteristics of 7-year-old trees and assuming constant slope geometry. By applying the cohesion, internal friction coefficient, and maximum dry density in the stability analysis model, the effect of soil parameters was investigated. Figure 7 shows behavior of the ML soil against tensions. CL soils with $19.2 \%$ Plasticity index, $5 \mathrm{kN} \mathrm{m}^{-2}$ cohesion, angle of internal friction $25^{\circ}$ and maximum dry density as $18 \mathrm{kN} \mathrm{m}^{-3}$, functioned weakly against applying tension, and transferred tension to the underlying layers and reduced the slope stability factor in CL soils, so that the slope stability factor for ML soil is 1.71 and for the CL soils is 1.48 (Figure 8). However, ML soil has a better performance against tensions by having a Plasticity index of $14.2 \%$, a cohesion of $8 \mathrm{kN} \mathrm{m}^{-2}$, angle of internal friction $29^{\circ}$ and a maximum dry density of $19 \mathrm{kN} \mathrm{m}^{-3}$. So soil type plays a very important role in the stability of forest embankments.

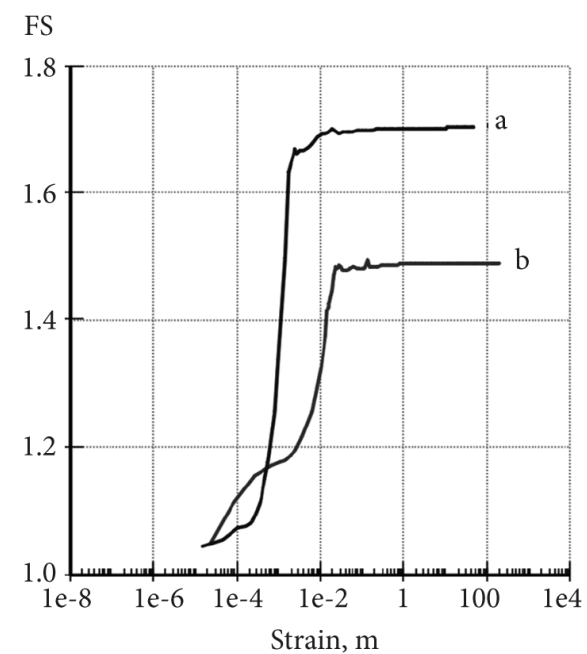

Figure 8. Slope Stability factors for different type of soil (a, Clayey Loam; b, Marl) 


\section{Discussion}

The root cohesion is added directly to the soil cohesion for the soil elements that are reinforced by plant roots (Chok et al., 2015). Additional root cohesion resulting from presence of root was calculated by Wu model in this study. The additional cohesion depends on the vegetation type and on the depth from soil surface (Kokutse et al., 2016). Studies by Pollen and Simon (2005) and Docker and Hubble (2008) indicated that estimated cohesion was a little above expected level. However, it has been used in many studies because of simplicity and accuracy (Gray \& Sotir, 1996; Operstein \& Frydman, 2000; Bischetti et al., 2005; Genet et al., 2005, 2008). Additional root cohesion resulting from the root changes under tensile strength of root and RAR level in different layers. Since tensile strength of roots does not much change in different ages, RAR index level plays determining role in different layers for additional root cohesion resulting from roots. In trees up to 7 years of age, the average cohesion in the soil layers for clay loam soils was $20.53 \mathrm{kPa}$ and $14.78 \mathrm{kPa}$ for marl soil. These values match to additional root cohesion calculated from roots with Abernethy and Rutherfurd (2001), Van Beek, Wint, Cammeraat, and Edwards (2005). These researchers proposed various models and calculated additional root cohesion below $20 \mathrm{kPa}$ for the roots.

The slope angle had the greatest impact on variation of factor of safety. Additional cohesion is regarded as the second most important parameter influencing the factor of safety (Kokutse et al., 2016). Vergani et al. (2014) noticed that the site-specific characterization of mechanical properties and root distribution is fundamental for the quantification of root reinforcement at the stand scale. Considering results of modeling of slope geometry and slope stability analysis in the stations, roots play effective role in level of stability of cutslopes and fillslopes. The overall slope's stability mainly depends on the depth of root's system and on additional cohesion provided by the roots (Temgoua, Kokutse, \& Kavazović, 2016). Analysis of tensions indicated that roots not only cause stability of layers in which they are present, but also cause reduction of tensions through influence on the underlying layers. In fact, increasing safety factor of soil layers increases safety factor of total soil mass. In the first station, (cutslope) root is absent and its functioning is vulnerable to landslide, and 0.28 increase in slope stability factor or FOS (about 12\% higher stability) caused turning slope status to stable state with stability factor above 1.5. While in the second station (fillslope), with 0.08 increase in slope stability factor by root of alder trees, instable state was turned into stable state with safety factor of 1.49 , but it is yet vulnerable to risk. The reason for less influence of roots on the stability may be characteristics of soil type in the second station. Such data as $c$ and of soil as well as soil $\gamma$ in saturated and unsaturated states significantly influence stability of embankment in stability analysis model. Since the measured values for testing shear strength of soil in second station (with marl soil type) are smaller than first station, influence of root on slope stability factor is calculated less than first station. It means that the lower soil layers are less influenced by the root.

Since surcharge pressure on embankments is one of the stability determinants, increasing age of trees in this study caused increasing weight and reducing stability of embankments. Considering results for calculation of slope stability factors for 7-years-old trees $(\mathrm{FOS}=1.54)$, 15 -years-old $(\mathrm{FOS}=1.47)$, and 20-years-old $(\mathrm{FOS}=1.33$ ) and in absence of trees (FOS $=1.44$ ), increasing age of trees not only does not help stabilization and reinforcement of soil, but also increases risk of landslide. Genet et al. (2008) used a similar analysis and found that slope stability factor for embankments with old trees on them are smaller than factors obtained for younger trees. Given factors calculated in this study, presence of old trees not only does not help stability of embankments, but also increases tension in the underlying layers. So that tensions are risen and extended to the layers, in which they are present. In this simulation, roots of young trees were able to increase slope stability by 6 percent, and turn the risky slope to a safe state. Number of trees is one of the major factors causing changes in safety factor. Two old alder trees, on average, impose pressure on embankment as large as 9 young trees and 3.5 middle-aged trees. Measurements showed that the RAR, RBD, and tensile strength indices do not differ significantly in different ages, which cause a large change in the stability factor. Therefore, what plays a decisive role in the rate of slope stability is the weight of trees. Also, 9 young alder trees in total (the total amount of cohesion created) can provide a higher RAR and a tensile strength than two trees, taking into account the same weight. In this simulation, based on age comparison, the number of trees for different ages was considered the same. However, if more young trees are to be considered for analysis according to the stand structure, the percentage increase in the slope stability factor will calculate greater than $6 \%$. Roering et al. (2003) stated that parts of embankment where root strength is less than other parts are more vulnerable to slide. Therefore, presence of young trees with denser planting intervals may reduce risk of landslide by filling the empty spaces.

\section{Conclusions}

In the current study, slope stability factor was calculated assuming fixed factors and applying change in soil type, which was determined based on USCS classification system for ML and CL soil types. According to the results, the foundation soil type may considerably influence stability of embankments. So that stability factor of ML soil embankment is higher than CL by 0.23 , which is due to mechanical characteristics of soil. Soil shear strength factors including angle of internal friction may change under influence by soil humidity. Soils with less cohesion and friction coefficient can withstand much less tension, and rupture faster and increase the chance of landslide. In this study, the soil ML has been able to record a greater safety 
factor than the CL soil due to its more additional root cohesion and angle of internal friction and lower plasticity index.

Investigating function of alder tree's root on reinforcement of slopes showed that if trees on the embankments are correctly managed, they could play a constructive role in the conservation of embankments' soil. Study results showed that RAR and RBD indices change depending on the soil characteristics and age of trees and their weight, and the change is sometimes considerable. However, following calculation of additional root cohesion resulting from root and applying it in slope stability model it is observed that a few $\mathrm{kPa}$ cannot have much effect on slope stability. Given slope geometry model and assuming weight of trees as zero, the roots can increase slope stability factor by about 20 percent, and it reduces by applying surcharge pressure (weight of trees), and sometimes this factor becomes negative due to increasing weight. The soil, as an important variable in the model under study, may reduce or increase slope stability through influence on distribution of tension and rooting pattern (ignored in this study). Therefore, considering research findings, root of trees (alder tree) can cause reinforcement and increase in stability of soil embankments, and factors such as soil and age directly and indirectly may influence slope stability.

\section{Acknowledgements}

This research did not receive any specific grant from funding agencies in the public, commercial, or not-for-profit sectors, and funded just by Sari University of Agricultural Sciences and Natural Resources as a PhD grant.

\section{Author contributions}

MN and ML conceived the study and were responsible for the design and development of the data analysis. MN was responsible for data collection. MN, ML and AM were responsible for the data analysis. MN and WW were responsible for data interpretation. MN wrote the first draft of the article.

\section{Disclosure statement}

The authors declare no conflict of interest.

\section{References}

Abernethy, B., \& Rutherfurd, I. D. (2001). The distribution and strength of riparian tree roots in relation to riverbank reinforcement. Hydrological Processes, 15, 63-79. https://doi.org/10.1002/hyp.152

Ali, N., Farshchi, I., Mu'azu, M. A., \& Rees, S. W. (2012). Soil-root interaction and effects on slope stability analysis. Electronic Journal of Geotechnical Engineering (EJGE) 17(C), 319-328. http://www.ejge.com/2012/Abs12.030.htm

Bischetti, G. B., Chiaradia, E. A., Simonato, T., Speziali, B., Vitali, B., Vullo, P., \& Zocco, A. (2005). Root strength and root area ratio of forest species in Lombardy (Northern Italy).
Plant Soil, 278, 11-22. https://doi.org/10.1007/s11104-0050605-4

Cofie, P., Koolen, A. J., \& Perdok, U. D. (2000). Measurement of stress-strain relationship of beech roots and calculation of the reinforcement effect of tree roots in soil-wheel systems. Soil and Tillage Research, 57, 1-12.

https://doi.org/10.1016/S0167-1987(00)00126-4

Chok, Y. H., Jaksa, M. B., Kaggwa, W. S., \& Griffiths, D. V. (2015). Assessing the influence of root reinforcement on slope stability by finite elements. International Journal of Geo-Engineering, 6, 12. https://doi.org/10.1186/s40703-015-0012-5

Docker, B. B., \& Hubble, T. C. T. (2008). Quantifying the enhanced soil shear strength beneath four riparian tree species. Geomorphology, 100, 401-418.

https://doi.org/10.1016/j.geomorph.2008.01.009

Genet, M., Stokes, A., Salin, F., Mickovski, S. B., Fourcaud, T., Dumail, J. F., \& Van Beek, R. (2005). The influence of cellulose content on tensile strength in tree roots. Plant and Soil, 278, 1-9. https://doi.org/10.1007/s11104-005-8768-6

Genet, M., Kokutse, N., Stokes, A., Fourcaud, T., Cai, X., Ji, J., \& Mickovski, S. (2008). Root reinforcement in plantations of Cryptomeria japonica D. Don: effect of tree age and stand structure on slope stability. Forest Ecology and Management, 256, 1517-1526. https://doi.org/10.1016/j.foreco.2008.05.050

Gentile, F., Elia, G., \& Elia, R. (2010). Analysis of the stability of slopes reinforced by roots. Design and Nature V. 138, 189200. https://doi.org/10.2495/DN100171

Gray, D. H., \& Sotir, R. B. (1996). Biotechnical and Soil Bioengineering Slope Stabilization: A Practical Guide for Erosion Control. John Wiley \& sons, Inc.

John, B., Pandey, H. N., \& Tripathi, R. S. (2001). Vertical distribution and seasonal changes of fine and coarse root mass in Pinus kesiya Royle Ex. Gordon forest of three different ages. Acta Oecologica, 22, 293-300.

https://doi.org/10.1016/S1146-609X(01)01118-3

Keyes, M. R., \& Grier, C. C. (1981). Above- and below-ground net production in 40-yearsold Douglas-fir stands on low and high productivity sites. Canadian Journal of Forest Research, 11, 599-605. https://doi.org/10.1139/x81-082

Kokutse, N. K., Temgoua, A. G. T., \& Kavazović, Z. (2016). Slope stability and vegetation: Conceptual and numerical investigation of mechanical effects. Ecological Engineering, 86, 146153. https://doi.org/10.1016/j.ecoleng.2015.11.005

Operstein, V., \& Frydman, S. (2000). The influence of vegetation on soil strength. Ground Improvement, 4(2), 81-89. https://doi.org/10.1680/grim.2000.4.2.81

Pollen, N., \& Simon, A. (2005). Estimating the mechanical effects of riparian vegetation on stream bank stability using a fiber bundle model. Water Resources Research, 41(7), W07025. https://doi.org/10.1029/2004WR003801

Reubens, B., Poesen, J., Danjon, F., Geudens, G., \& Muys, B. (2007). The role of fine and coarse roots in shallow slope stability and soil erosion control with a focus on root system architecture: a review. Trees Structure and Function, 21(4), 385-402. https://doi.org/10.1007/s00468-007-0132-4

Roering, J. J., Schmidt, K. M., Stock, J. D., Dietrich, W. E., \& Montgomery, D. R. (2003). Shallow landsliding, root reinforcement, and the spatial distribution of trees in the Oregon Coast Range. Canadian Geotechnical Journal, 40(2), 237-253. https://doi.org/10.1139/t02-113

Schmidt, K. M., Roering, J. J., Stock, J. D., Dietrich, W. E., Montgomery, D. R., \& Schaub, T. (2001). The variability of root cohesion as an influence on shallow landslide susceptibility in the Oregon Coast Range. Canadian Geotechnical Journal, 
38(5), 995-1024. https://doi.org/10.1139/t01-031

Temgoua, A. G. T., Kokutse, N. K., \& Kavazović, Z. (2016). Influence of forest stands and root morphologies on hillslope stability. Ecological Engineering, 95, 622-634. https://doi.org/10.1016/j.ecoleng.2016.06.073

Van Beek, L. P. H., Wint, J., Cammeraat, L. H., \& Edwards, J. P. (2005). Observation and simulation of root reinforcement on abandoned Mediterranean slopes. Plant and Soil, 278(1-2), 55-74. https://doi.org/10.1007/s11104-005-7247-4

Vergani, C., Schwarz, M., Cohen, D., Thormann, J. J., \& Bischetti, G. B. (2014). Effects of root tensile force and diameter distribution variability on root reinforcement in the Swiss and Italian Alps. Canadian Journal of Forest Research, 44(11), 1426-1440. https://doi.org/10.1139/cjfr-2014-0095

Wu, T. H., McKinnell III, V. P., \& Swanston, D. N. (1979). Strength of tree roots and landslides on Prince of Wales Island, Alaska. Canadian Geotechnical Journal, 16(1), 19-33. https://doi.org/10.1139/t79-003

Zhou, Y. Y., \& Wang, X. M. (2018). Mesomechanics characteristics of soil reinforcement by plant roots. Bulletin of Engineering Geology and the Environment, 78(5), 3719-3728.

https://doi.org/10.1007/s10064-018-1370-y 